\title{
Improved lung function and symptom control with formoterol on demand in
} asthma

\author{
D. Cheung*, H.C.J. van Klink" and R. Aalbers", for the OZON study group
}

ABSTRACT: Many asthma patients remain symptomatic despite maintenance therapy with inhaled corticosteroids (ICS) and salbutamol as rescue medication. In the present study the relative efficacy and preference for as-needed formoterol compared with salbutamol was examined.

In total, $\mathbf{2 1 1}$ patients with a mean age of $\mathbf{4 5}$ yrs (mean forced expiratory volume in one second (FEV 1 ) 77\% predicted normal), using ICS, were randomised to 3 weeks' double-blind treatment with as-needed formoterol $4.5 \mu \mathrm{g}$ Turbuhaler ${ }_{\circledR}$ and with as-needed salbutamol $100 \mu \mathrm{g}$ Turbuhaler in a cross-over fashion.

Overall, lung function and symptom control were better with as-needed formoterol than with asneeded salbutamol. During as-needed formoterol treatment daytime and night-time symptom scores were lower, peak expiratory flow and FEV 1 were higher and patients experienced fewer disturbed nights (34\%) compared with as-needed salbutamol. Patients preferred the formoterol treatment to salbutamol. Of the 162 patients expressing a preference, formoterol was preferred by $68 \%$ (95\% confidence interval: 60-75). Subjective assessment of effectiveness also favoured formoterol, which was perceived as slightly faster acting than salbutamol.

In conclusion, as-needed formoterol improved symptoms and lung function compared with salbutamol and was perceived as more effective and at least as fast acting for symptom relief.

\section{KEYWORDS: Asthma, formoterol turbuhaler, reliever, salbutamol}

$\mathbf{T}$ he $\beta_{2}$-agonists are widely used in the treatment of asthma for relief of bronchoconstriction. Due to their established efficacy and safety profile they have reached a prominent place in the management of asthma [1]. Rapid-acting $\beta_{2}$-agonists, such as salbutamol (albuterol) and terbutaline, are primarily used for as-needed therapy, whilst $\beta_{2}$-agonists with a long duration of effect, such as salmeterol and formoterol, are generally reserved for maintenance treatment in conjunction with inhaled corticosteroids (ICS). However, formoterol, unlike salmeterol, has a rapid onset of bronchodilation, which allows it to be used both for maintenance and as-needed therapy [2-5]. Adding a long-acting $\beta_{2}$-agonist to ICS therapy, as a maintenance treatment, has been shown to reduce the frequency of asthma exacerbations [6, 7]. Another study has shown that as-needed formoterol can reduce the incidence of severe asthma exacerbations compared with as-needed terbutaline [8], with lower overall management costs [9].
At the start of the present study, no published studies were available examining the relative efficacy of inhaled formoterol in comparison with inhaled salbutamol, with both treatments used strictly as needed. However, recently, an open comparison of formoterol and salbutamol showed that the use of as-needed formoterol was associated with improved asthma control [10]. The primary aim of the present study was to investigate relative efficacy and patient preference for formoterol and salbutamol when used only as reliever medication. Having both $\beta_{2^{-}}$ agonists available in identical inhalers made it possible to assess the relative efficacy of the two drugs in a double-blind, controlled setting in a cross-over design. It was anticipated that by allowing free as-needed use of both drugs, the patients would compensate for the shorter duration of action of salbutamol by taking more frequent inhalations. If this theory reflected actual patient behaviour during the study, a likely outcome would be a similar efficacy between the two treatments. Therefore, an

\section{AFFILIATIONS}

*Dept of Pulmonology, Vlietland Hospital, Schiedam,

\# Dept of Pulmonology,

Diaconessenhuis, Leiden, and

'Martini Hospital, Groningen, The Netherlands.

CORRESPONDENCE

D. Cheung

Dept of Pulmonology

Vlietland Hospital

Burg. Knappertlaan 25

NL-3116 BA Schiedam

The Netherlands

Fax: 31102044784

E-mail: dcheung@ssvz.nl

Received:

January 192005

Accepted after revision:

November 072005

SUPPORT STATEMENT

The present study was financially supported by AstraZeneca BV, Zoetermeer, The Netherlands (study number BN-00D-0029). 
additional aim of the current study was to investigate patients' preference for the study drugs, which was made possible by the double-blind and cross-over design of the study.

\section{METHODS}

\section{Patient characteristics}

Adult patients ( $\geqslant 18 \mathrm{yrs}$ ) with a diagnosis of asthma according to the American Thoracic Society (ATS) [11] were studied. Enrolled patients were on ICS treatment for $>4$ weeks. This treatment was maintained throughout the study. All patients included had a baseline forced expiratory volume in one second $(\mathrm{FEV} 1) \geqslant 50 \%$ of predicted normal value [12] and FEV1 reversibility $\geqslant 12 \%$ after inhaling terbutaline $1.0 \mathrm{mg}$ or salbutamol $0.4 \mathrm{mg}$. Patients were excluded from the study if they: 1) used systemic glucocorticosteroids; 2) experienced a clinically relevant airway infection in the 4 weeks before the study; 3 ) had a clinically relevant concomitant disease; and 4) used $\beta$-blocker therapy or were pregnant or breastfeeding. Systemic bronchodilators were not allowed and all inhaled bronchodilators were stopped at enrolment and exchanged for the study drugs.

\section{Study design}

The randomised, double-blind, cross-over study was performed in 27 centres in the Netherlands. Eligible patients entered a run-in period (14 days) in which they continued their ICS at a constant dose and all reliever and maintenance bronchodilators were exchanged for terbutaline (Bricanyl ${ }_{\circledR}$ Turbuhaler ${ }^{\circledR}$ $0.25 \mathrm{mg}$; AstraZeneca, Zoetermeer, the Netherlands) to be used only as needed. Reliever use was recorded using a daily diary card. Patients requiring $\geqslant 10$ inhalations of terbutaline over the run-in period, but $\leqslant 8$ inhalations on any single day were randomised. At randomisation, the reliever medication was exchanged for blinded study inhalers, consisting of formoterol $4.5 \mu \mathrm{g}$ (delivered dose, equivalent to $6 \mu \mathrm{g}$ metered dose; Oxis $₫$ Turbuhaler ${ }^{\circledR}$, AstraZeneca) or salbutamol $100 \mu \mathrm{g}$ (albuterol; salbutamol Turbuhaler ${ }^{\circledR}$, AstraZeneca). After 3 weeks of treatment patients were switched to the alternative inhaler for another 3 weeks. The current study was performed according to Good Clinical Practice guidelines and was subjected to approval by Medical Ethics Committees at all centres. All patients gave written informed consent before being enrolled.

\section{Efficacy measurements}

\section{Lung function}

Peak expiratory flow (PEF) was recorded twice daily (miniVitalograph Absolute Scale; Vitalograph, Buckingham, UK) on daily diary cards throughout the study. FEV1 and forced vital capacity (FVC) were measured at the clinic visits and the highest values of both parameters recorded. All apparatus fulfilled the ATS specifications for accuracy.

\section{Preference}

After the second treatment period, patients were given a questionnaire in Dutch that assessed their overall preference for either the first or second treatment, or if they had no preference for either of the test treatment periods. The two questions were as follows. 1) Which treatment period out of the last 6 weeks do you prefer in general for use of your rescue medication for your asthma, treatment period 1 or treatment period 2? 2) You have been requested to express a preference, but if you have no preference at all for either treatment period you may choose no preference.

\section{Symptoms}

Daytime and night-time asthma symptoms were recorded on a scale of $0-3 \quad(0=$ none; $1=$ mild; $2=$ moderate; and $3=$ severe symptoms). Awakenings due to asthma and daily bronchodilator use were also recorded.

\section{Subjective efficacy}

After the first and second treatment period, patients completed a questionnaire with four questions using a $100-\mathrm{mm}$ visual analogue scale (VAS). This questionnaire assessed the patient's perception of: 1) speed of onset of relief, i.e. "How fast did you have benefit after using an inhalation from your study medication?"; 2) duration of effect, i.e. "How long did you have benefit after using an inhalation of your study medication?"; 3) overall effectiveness of the relief inhaler, i.e. "How do you think the study medication has worked for you?"; and 4) their asthma in general, i.e. "How did you feel in general about your asthma during the past 3 weeks?" A score of zero represented the worst possible opinion and a score of 100 represented the best possible.

\section{Analysis}

The present study was designed to be of sufficient size to detect a clinically relevant preference for formoterol or for salbutamol. It was anticipated that a difference in efficacy parameters might not be detectable due to patients titrating each study drug to get minimal symptoms; therefore, preference was chosen as a primary parameter. A statistically significant preference was defined as one of the two study drugs preferred by significantly $>50 \%$ of all treated patients. The minimal clinically relevant preference was estimated to be $60 \%$. Therefore, with $80 \%$ power and a two-sided significance level of $5 \%, 200$ patients were required to be randomised and 120 patients were required to prefer one treatment in order to show a statistically significant preference. Preference was calculated both for all randomised patients and for the group that expressed a preference. Spirometry and VAS were analysed by analysis of variance (intent-to-treat analysis), with patient, period and treatment as factors. For FEV1 an additional exploratory analysis was performed, including only the patients who did not use a dose of their bronchodilator in the previous $6 \mathrm{~h}$. PEF values, day and night symptom scores, and as-needed reliever medication use were averaged over the entire treatment periods. PEF variability was calculated as the quotient of the absolute difference between morning and evening PEF (PEFam and PEFpm, respectively) and the mean PEF over that day. Symptom-free days (SFD) were defined as a day with both morning and evening symptom score equal to zero and no awakenings due to asthma. All hypotheses were made using two-sided alternatives. A p-value $<5 \%$ was considered statistically significant.

An exploratory analysis was performed post hoc to investigate differences in preference and VAS outcomes assessed by a questionnaire in patients who used frequent or less frequent as-needed doses of terbutaline in the run-in period. The study population was divided into three tertiles of approximately 
equal size, depending on the mean number of daily doses of terbutaline in the run-in: low $<1.58$ doses day $^{-1} \quad(n=69)$; intermediate $1.58-2.80$ doses $\cdot$ day $^{-1}(n=70)$; and high $>2.80$ doses $\cdot$ day $^{-1}(n=72)$.

\section{RESULTS}

Of the 251 patients enrolled, 211 were randomised (first treatment: formoterol $n=106$, salbutamol $n=105)$. During the run-in period 40 patients were excluded, mainly due to deviations from the terbutaline-use criteria. Patients had moderate-to-severe asthma (mean FEV1 77\% pred normal) and displayed $18 \%$ reversibility in FEV1 (table 1). According to the Global Initiative for Asthma (GINA) classification of asthma severity [1], 79 patients had intermittent asthma (step 1), eight had mild persistent asthma (step 2), 90 had moderate persistent asthma (step 3) and 34 had severe persistent asthma

\section{TABLE 1 Demographic data}

All randomised patients

$\begin{array}{lc}\text { Subjects } \mathbf{n} & 211 \\ \text { Males } & 105(50) \\ \text { Mean age yrs } & 44.7 \pm 13.4 \\ \text { Smoking habit (non/ex/current) } & 94 / 88 / 29 \\ \text { Mean FEV } \mathbf{1} \text { L } & 2.59 \pm 0.75 \\ \text { Mean FEV } \mathbf{1} \% \text { pred } & 77.1 \pm 14.7 \\ \text { Mean reversibility L } & 0.45 \pm 0.17 \\ \text { Mean \% reversibility } & 17.7 \pm 6.4 \\ \text { Mean reversibility \% pred } & 13.3 \pm 4.3 \\ \text { Mean FVC L } & 3.89 \pm 1.09 \\ \text { Mean ICS dose } \boldsymbol{\mu g} \cdot \text { day }^{-\mathbf{1}} & 797 \pm 338\end{array}$

Data are presented as $n(\%)$ or mean \pm SD, unless otherwise stated. FEV 1 : forced expiratory volume in one second; \% pred: percentage predicted; FVC: forced vital capacity; ICS: inhaled corticosteroids. (step 4). The mean dose of ICS was $797 \mu \mathrm{g} \cdot \mathrm{day}^{-1}$ (19 patients took beclomethasone, 103 budesonide and 87 fluticasone), indicating that patients had predominantly moderate-to-severe asthma. Of the randomised patients, 14 (7\%) did not complete both treatment periods (formoterol $n=6$, salbutamol $n=8$ ), nine were withdrawn due to adverse events (AEs; formoterol $n=4$, salbutamol $n=5$ ) and five due to withdrawal of consent or the use of prohibited medication.

\section{Efficacy}

There were large differences in both objective and subjective efficacy assessments (table 2). FEV1 after formoterol treatment was $5 \%$ higher than after salbutamol treatment (mean difference $0.12 \mathrm{~L}$; $95 \%$ confidence interval (CI) $0.07-0.16$; $p<0.0001)$. Similar differences were observed in the exploratory analysis of the 174 patients who did not use a dose of their study drug, in at least the last $6 \mathrm{~h}$, prior to spirometry on both occasions (mean difference 0.11 L; 95\% CI 0.07-0.15; p<0.001). Other significant differences in lung function measures in favour of formoterol were: FVC (mean difference of $0.07 \mathrm{~L}$; 95\% CI 0.02-0.13; $\mathrm{p}<0.01)$; PEFam $\left(13.8 \mathrm{~L} \cdot \mathrm{min}^{-1} ; 95 \%\right.$ CI 10.0 17.6; $\mathrm{p}<0.0001)$; and PEFpm (13.7 L. $\mathrm{min}^{-1} ; 95 \%$ CI 9.2-18.1; $\mathrm{p}<0.0001)$. PEF variability did not differ. After formoterol treatment FEV1 was $80.5 \%$ pred, and $77.1 \%$ pred after salbutamol treatment (mean difference 3.5\%; 95\% CI 2.2-4.8\%).

Within the study population of 211 patients, the preference for formoterol did not differ significantly from the predefined $50 \%$ level $(p=0.58)$, but the preference for salbutamol was significantly $<50 \%(\mathrm{p}<0.0001)$. In total, 110 patients $(52.1 \%)$ preferred formoterol (95\% CI 45.2-59.0), 52 patients $(24.6 \%)$ preferred salbutamol (95\% CI 19.0-31.0), 37 patients had no preference for either treatment period and 12 patients were withdrawn prior to being able to express their preference (fig. 1). Within the population of 162 patients expressing any preference, there was a 2.1 -fold preference for formoterol with formoterol preferred by $67.9 \%(95 \%$ CI 60.1-75.0; $\mathrm{p}<0.001)$ and salbutamol by the remaining $32.1 \%$ (95\% CI 25.0-39.9;

TABLE 2 Lung function and subjective efficacy measures

\begin{tabular}{|c|c|c|c|c|c|}
\hline & Terbutaline run-in & Formoterol period & Salbutamol period & Treatment difference & p-value \\
\hline FEV 1 L & $2.62 \pm 0.81$ & $2.71 \pm 0.83$ & $2.59 \pm 0.85$ & $0.12(0.07-0.16)$ & $<0.0001$ \\
\hline FVC L & $3.87 \pm 1.16$ & $3.96 \pm 1.16$ & $3.88 \pm 1.18$ & $0.07(0.02-0.13)$ & $<0.01$ \\
\hline Morning PEF L·min ${ }^{-1}$ & $363 \pm 101$ & $372 \pm 110$ & $358 \pm 110$ & $13.8(10.0-17.6)$ & $<0.0001$ \\
\hline Evening PEF L. $\min ^{-1}$ & $380 \pm 102$ & $386 \pm 109$ & $372 \pm 109$ & $13.7(9.2-18.1)$ & $<0.0001$ \\
\hline Night-time symptoms $0-3$ & $0.57 \pm 0.53$ & $0.49 \pm 0.55$ & $0.56 \pm 0.56$ & $0.07(0.03-0.11)$ & $<0.001$ \\
\hline Daytime symptoms $0-3$ & $1.01 \pm 0.48$ & $0.87 \pm 0.57$ & $0.98 \pm 0.57$ & $0.11(0.07-0.26)$ & $<0.0001$ \\
\hline $\begin{array}{l}\text { Nocturnal awakenings due to } \\
\text { asthma } \text { week }^{-1}\end{array}$ & $0.83 \pm 1.29$ & $0.71 \pm 1.44$ & $1.06 \pm 1.62$ & $0.36(0.20-0.51)$ & $<0.0001$ \\
\hline Inhalations $\cdot 24 \mathrm{~h}^{-1}$ & $2.40 \pm 1.33$ & $2.26 \pm 1.45$ & $2.48 \pm 1.50$ & $0.22(0.11-0.34)$ & $<0.001$ \\
\hline Symptom-free days per period & $2.4 \pm 4.0$ & $5.8 \pm 7.7$ & $4.8 \pm 6.9$ & $1.1(0.4-1.7)$ & $<0.001$ \\
\hline VAS: “How fast benefit...” & & $54.0 \pm 21.2$ & $50.3 \pm 23.3$ & $3.7(-0.0-7.5)$ & 0.051 \\
\hline VAS: “How long benefit...” & & $58.6 \pm 24.1$ & $54.2 \pm 23.7$ & $4.3(0.3-9.0)$ & 0.067 \\
\hline VAS: "How well did it work..." & & $62.0 \pm 23.0$ & $53.7 \pm 24.2$ & $8.3(4.9-11.7)$ & $<0.0001$ \\
\hline VAS: “Asthma in general...” & & $64.1 \pm 22.5$ & $57.1 \pm 22.4$ & $6.9(3.2-10.6)$ & $<0.001$ \\
\hline
\end{tabular}

Data are presented as mean \pm SD or mean (95\% confidence interval). FEV1: forced expiratory volume in one second; FVC: forced vital capacity; PEF: peak expiratory flow; VAS: visual analogue scale $(0-100 \mathrm{~mm})$. 

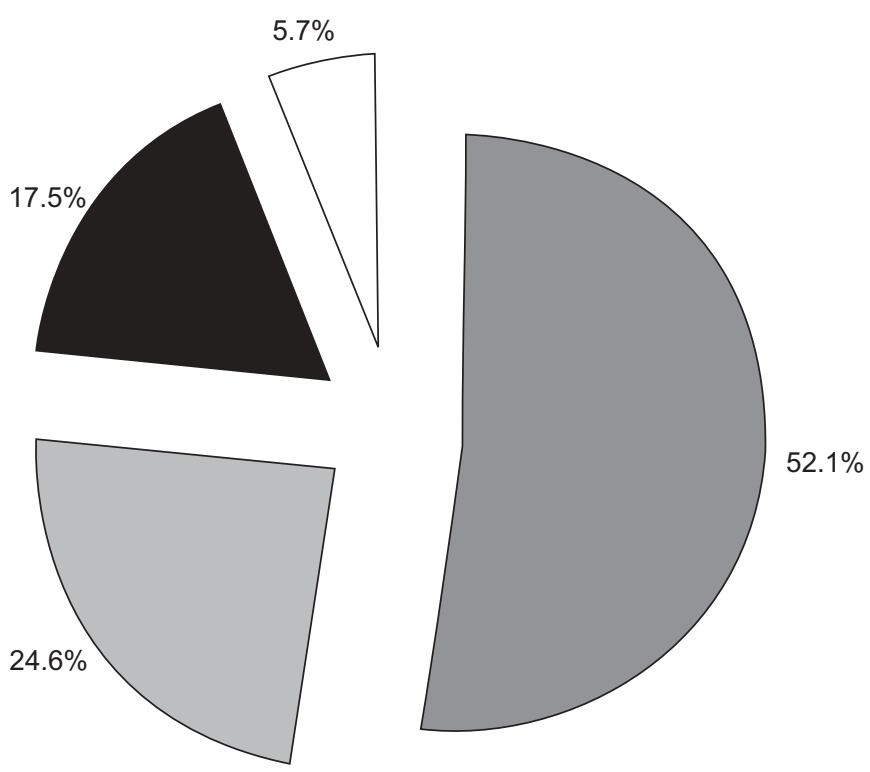

FIGURE 1. Proportion of all randomised patients expressing a preference for as-needed medication. $\square$ : withdrawn; $\mathbf{\square}$ : formoterol; $\square$ : salbutamol; $\mathbf{\square}$ : no preference.

$p<0.0001)$. There was a small and nonsignificant 1.3 -fold preference for the second period, which had no influence on the main outcome, as an equal number of patients started with either treatment.

Daytime and night-time asthma symptoms differed between the two treatments in favour of formoterol. Mean night-time asthma symptom score was $13 \%$ lower during formoterol treatment (mean difference $0.07 ; 95 \%$ CI $0.03-0.11 ; \mathrm{p}<0.001$ ) and daytime symptoms were $11 \%$ lower (mean difference 0.11 ; 95\% CI 0.07-0.26; $\mathrm{p}<0.0001)$. In addition, during formoterol treatment patients had $34 \%$ fewer nights in which sleep was disturbed by asthma symptoms (mean difference 0.36 nights week $^{-1}$; 95\% CI $\left.0.20-0.51 ; \mathrm{p}<0.0001\right)$. During formoterol treatment, patients had $23 \%$ more SFD (5.8 versus 4.8 days. period $^{-1}$, mean difference 1.1 days; 95\% CI 0.4-1.7; $\mathrm{p}<0.001$ ). On $14 \%$ of the days in both treatment periods no as-needed inhalations were used. Patients required 9\% fewer inhalations of formoterol compared with salbutamol (mean difference 0.22 inhalations $\cdot$ day $^{-1} ; 95 \%$ CI $\left.0.11-0.34 ; \mathrm{p}<0.001\right)$. The cumulative frequency distribution of the number of days with a specific number of doses indicated a turning point between 3-4 doses $\cdot$ day $^{-1}$. Days with less than three doses were more common during formoterol treatment, while days with more than four doses were more common during salbutamol treatment.

Patients' perception of the effectiveness of relief medication on the VAS showed that they rated formoterol to be more effective than salbutamol treatment on all attributes assessed (table 2). Two questions resulted in significant differences: 1) "How well did the study drug work for you?"; and 2) "How did you feel in general about your asthma?" (Both $p<0.001$ ). Perceived duration of effect did not reach the formal significance level between the two groups ( $p=0.067)$. Surprisingly, there was a difference in perceived onset of action in favour of formoterol, although this was not significantly different $(p=0.051)$.
An analysis performed post hoc on the data with the patient population split into three tertiles indicated that all tertiles gained increased benefit with formoterol compared with salbutamol (fig. 2). The difference in the number of as-needed inhalations was largest in the intermediate- and high-use tertiles $\left(\geqslant 1.58\right.$ doses terbutaline $\cdot$ day $\left.^{-1}\right)$. These two groups also had the largest difference in favour of formoterol for treatment preference ( $\geqslant 2.3$-fold versus salbutamol, data not shown). The most marked difference in perceived effectiveness and duration of effect was observed in these two groups using an intermediate or high number of terbutaline inhalations in the run-in. In contrast, the difference in perceived speed of onset of effect in favour of formoterol was greatest in the group who used a low number of terbutaline inhalations in the run-in.

\section{Safety}

There was no difference in the incidence of AEs in the two treatment periods (formoterol treatment: 47 events; salbutamol treatment: 50 events). The most frequently reported AEs ( $>2 \%$ of the study population) were respiratory tract infections (nine in the formoterol group and 18 in the salbutamol group); headache (five formoterol, four salbutamol); and asthma deterioration (four formoterol, five salbutamol). Nine patients were withdrawn due to AEs; four patients in the formoterol group (three due to asthma exacerbation and one due to palpitations) and five patients in the salbutamol group (two due to asthma exacerbation, one due to headache, one due to respiratory tract infection and one due to worsening of cholelithiasis). There were few asthma exacerbations during the study requiring a prednisolone course and one patient on salbutamol treatment was hospitalised for an exacerbation.

\section{DISCUSSION}

The present study showed that during salbutamol treatment asthma patients did not titrate their as-needed use to an optimal level. During treatment with formoterol a higher level of asthma control was obtained, defined as better symptom control and superior lung function, than during salbutamol treatment when both were used as needed by patients with moderate-to-severe asthma. Statistically significant and clinically relevant differences were observed in FEV1, PEF, daytime and night-time asthma symptoms in favour of formoterol. This improved clinical efficacy was accompanied by a 2.1-fold greater preference for formoterol and by a difference in patients' perception of the overall effectiveness of treatment.

As expected, the number of daily as-needed inhalations was significantly lower during formoterol treatment, a consequence of the drugs long duration of action [2]. The relatively small difference $(9 \%)$ may be partly explained by including patients with low or infrequent as-needed use, i.e. those mainly using a single daily dose upon rising or before going to sleep. These patients were likely to record a similar number of inhalations while being treated with a short-acting or a long-acting bronchodilator. The current study also shows that while using salbutamol as needed, the patients in the present study did not increase the frequency of reliever use to gain maximal attainable bronchodilating effect and minimal symptoms. In theory, by increasing the frequency of inhalations of the shortacting bronchodilator, a similar bronchodilating effect should be attainable as when using the long-acting bronchodilator at a 


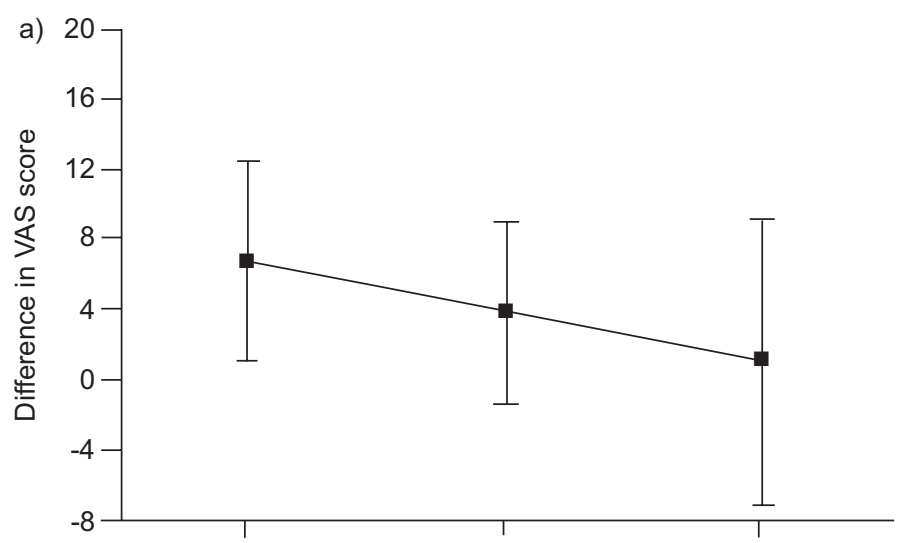

b)
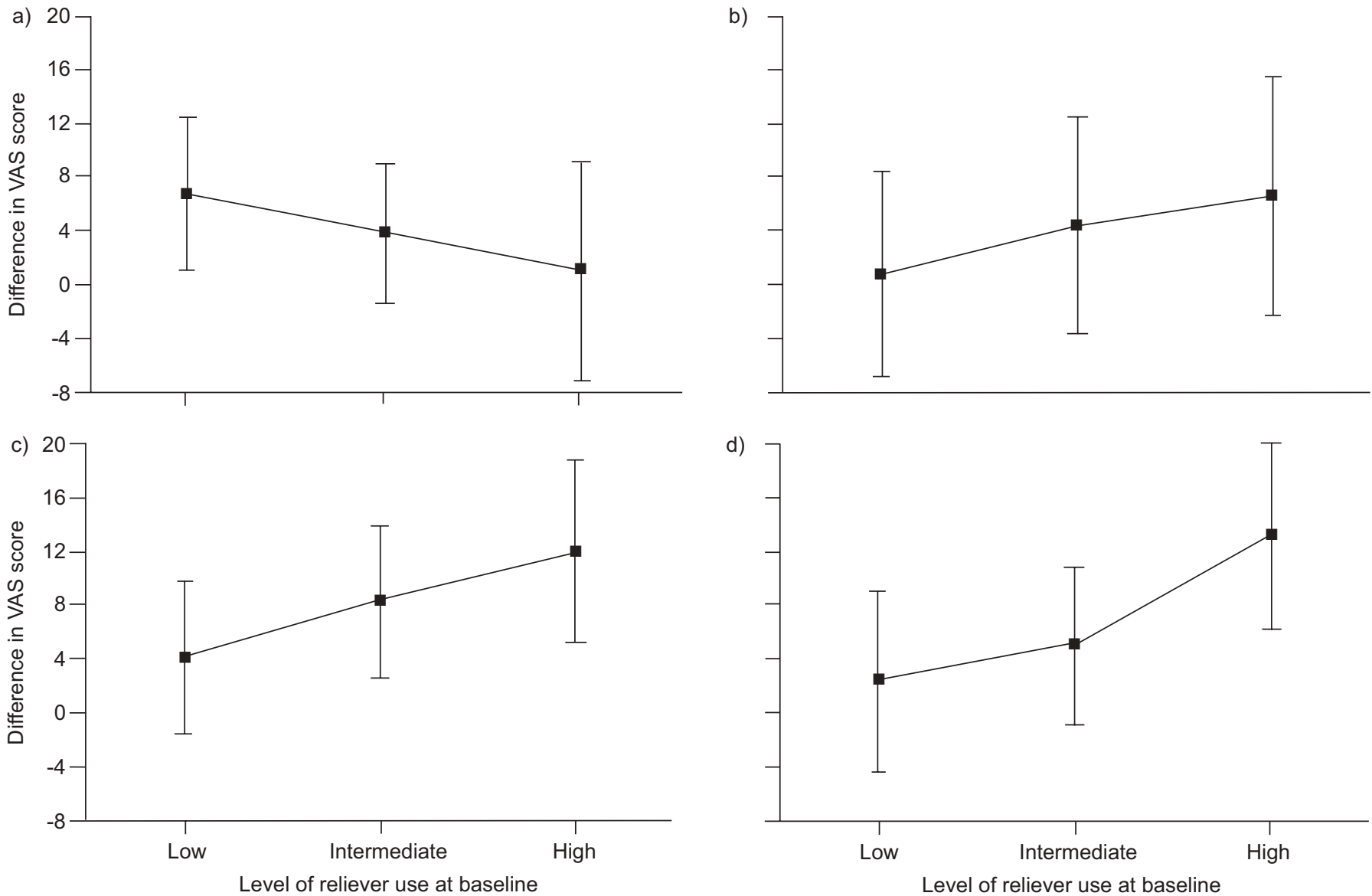

d)

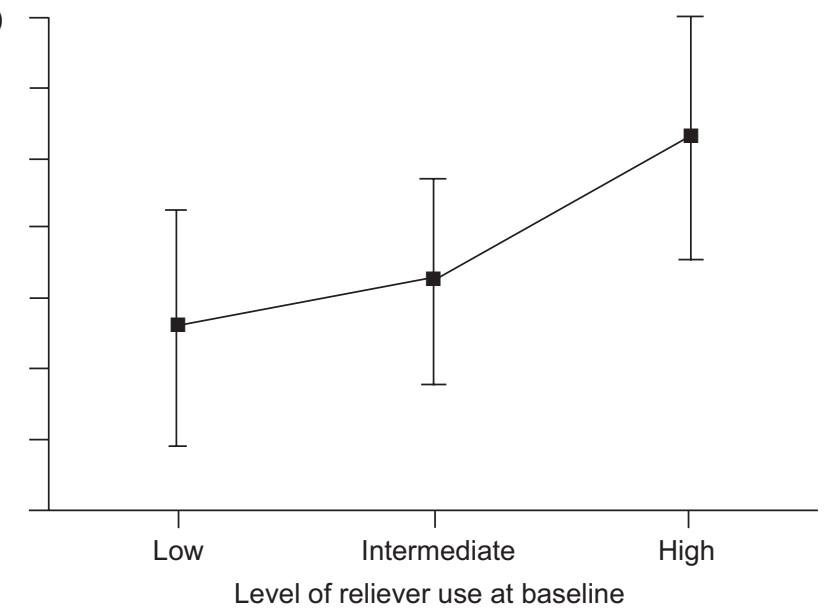

FIGURE 2. Difference in subjective effectiveness, assessed via visual analogue scales (VAS $(0-100 \mathrm{~mm})$; mean $\pm 95 \%$ confidence interval formoterol minus salbutamol) in three subgroups, based on their as-needed terbutaline use in the run-in period. a) "How fast did you feel a benefit?"; b) "How long did you feel a benefit?"; c) "How well did the study drug work for you?"; and d) "How in general did you feel about your asthma?" Low: <1.58 doses.day ${ }^{-1}$; intermediate: $1.58-2.80$ doses·day ${ }^{-1}$; and high: $>2.80$ doses $\cdot$ day $^{-1}$.

lower frequency. In real life, patients seem to settle for worse symptom control while being treated with salbutamol than when treated with formoterol.

An exploratory analysis was performed post hoc, splitting the study population into three equal groups with a higher, medium or lower use of as-needed medication during the runin. Efficacy differences between formoterol and salbutamol existed in all three groups, but the patients in the two groups with the highest use of reliever medication during run-in $\left(\geqslant 1.58\right.$ doses $\cdot$ day $\left.^{-1}\right)$ showed the largest differences in asneeded medication use, overall preference towards formoterol and subjective effectiveness in favour of formoterol. This suggests that more frequent users of as-needed treatment will benefit the most from the longer duration of action of formoterol. In contrast, the subgroup with the lowest use of reliever medication reported formoterol to work faster than salbutamol, which may indicate that frequent users may have a poorer perception of a bronchodilating effect.

There were no differences in the incidence (or profile) of AEs or asthma exacerbations between the two study drugs. In total there were 24 patient-yrs of observation in the present study in which only one hospitalisation due to an asthma exacerbation occurred and only five patients $(2 \%)$ required systemic corticosteroid therapy. The short assessment period per patient in the present study limited the ability to detect a small difference in AE profile, but a favourable safety profile for asneeded formoterol was shown in two other large, blinded, long-term studies in comparison with as-needed terbutaline [8, 13] and in a recently published study versus open label asneeded salbutamol [10]. Nevertheless, all symptom, lung function and preference measures appropriate for a 3-week assessment period significantly favoured treatment with asneeded formoterol. Indeed, the current study is one of the first to demonstrate improved symptom control with as-needed formoterol versus as-needed salbutamol.

In the present study, each treatment was administered for 3 weeks. This allowed patients to recall their asthma status in the first period when answering questions on treatment preference on completion of the second treatment period. As patients were instructed to use each treatment strictly as needed and not regularly, it was anticipated that steady state would be reached fairly quickly and carry-over effects would be minimal.

Many aspects of reliever medication will have an impact on preference. The present study was performed with identical and blinded inhalers, so the ease of use of inhaler could have 
no influence on the outcome. The higher preference for formoterol was more likely to be related to other factors, such as the observed difference in clinical effect. Patients were asked to rate four subjective aspects of the study treatments using the VAS. All four showed formoterol to be rated as more effective than salbutamol, although only two of these were statistically significant. Patients also perceived formoterol to have at least as fast an onset of effect as salbutamol.

The benefits of as-needed formoterol were further corroborated by traditional efficacy parameters, such as a $5 \%$ increase in FEV1, a $23 \%$ increase in the number of SFD and a $34 \%$ lower incidence of awakenings due to asthma.

It remains unclear whether the observed difference in overall clinical effect with formoterol relates solely to its longer duration of action or to other specific properties. In one comparative study, as-needed formoterol compared with asneeded terbutaline reduced the incidence of severe asthma exacerbations by $45 \%$ [8]. Furthermore, other studies have shown that regular formoterol treatment leads to a decrease in severe exacerbations [6, 7]. Possible explanations for the benefits of formoterol in asthma may be found in the observation that formoterol enhances the anti-inflammatory effects of corticosteroids in vitro [14]. Interestingly, formoterol has been shown to decrease the presence of eosinophils in the airway mucosa and sputum of asthmatics [15-17], while in other recently published studies other $\beta_{2}$-agonists, such as terbutaline and salmeterol, did not significantly influence sputum or airway mucosa eosinophil content [18-20].

With the advent of combination therapy (ICS plus a longacting $\beta$-agonist) for maintenance treatment of more severe asthma, the possibility of using formoterol both as maintenance and as needed should be considered. IND et al. [13] showed that as-needed formoterol, in addition to regular doses as part of a combination regimen, was as well tolerated and as effective as terbutaline. Therefore, if formoterol can be easily substituted for other, short-acting rescue medications, this new practice trend should not affect the usefulness of as-needed formoterol. Indeed, there may be some inherent advantages to using formoterol as both maintenance and as-needed therapy, including a need for fewer inhalers, leading to improved adherence to treatment. Furthermore, the REal LIfe EFfectiveness of Oxis ${ }^{\circledR}$ Turbuhaler ${ }_{\circledR}$ as-needed in asthmatic patients (RELIEF) study [10] demonstrated that patients receiving maintenance long-acting $\beta$-agonists used a similar number of rescue inhalations of either formoterol or salbutamol, but that those without maintenance long-acting $\beta$-agonists used significantly more inhalations of salbutamol compared with formoterol.

In conclusion, in patients using inhaled corticosteroids as maintenance therapy, as-needed treatment with formoterol results in improved lung function and symptom control compared with as-needed salbutamol. Formoterol treatment was perceived to be at least as fast acting as salbutamol treatment and formoterol treatment was significantly preferred over salbutamol by asthma patients.

\section{ACKNOWLEDGEMENTS}

The following included patients in the present study: J. Asin, T.A. Bantje, W.G. Boersma, H.E.J. Sinninghe Damsté, J.J.P. den
Hertog, H. Dik, W.B.M. Evers, A.H.M. van der Heijden, A.F. Kuipers, J.L. van der Lichte, P.B. Luursema, B.J.M. Pannekoek, H.R. Pasma, W.R. Pieters, J.H.E.M. Schijen, A.P. Sips, R. Slotema, P.I. van Spiegel, I. Utama, G.T. Verhoeven, J. Westbroek, M. Westenend, F.A. Wilschut, G.J.M. van Doesburg, I.C. Spelt, J.M.M. van der Weerden, A. Veerman, W. Stenvers, and I.G.C.M. Bierens. The authors would like to thank the AstraZeneca study team for their help in monitoring the study and performing the statistical analysis: I. Stobbe ${ }^{\dagger}$; M. Tieleman; P. Gobbens; M. Plaisier; D. Neppelenbroek; H. Vliegenthart-de Gouw; R. Kalpoe and M. Boorsma. They would also like to thank C. McCann for editorial help with the manuscript.

\section{REFERENCES}

1 GINA Workshop Report: Global Strategy for Asthma Management and Prevention, available from http:// www.ginasthma.org. Date last accessed: Nov 2005. Date last updated: 2005.

2 van Noord JA, Smeets JJ, Raaijmakers JA, Bommer AM, Maesen FP. Salmeterol versus formoterol in patients with moderately severe asthma: onset and duration of action. Eur Respir J 1996; 9: 1684-1688.

3 van Noord JA, Smeets JJ, Maesen FPV. A comparison of the onset of action of salbutamol and formoterol in reversing methacholine-induced bronchoconstriction. Respir Med 1998; 92: 1346-1351.

4 Politiek MJ, Boorsma M, Aalbers R. Comparison of formoterol, salbutamol and salmeterol in methacholineinduced severe bronchoconstriction. Eur Respir J 1999; 13: 988-992.

5 Seberová E, Andersson A. Oxis (formoterol given by Turbuhaler) showed as rapid an onset of action as salbutamol given by a pMDI. Respir Med 2000; 94: 607-611.

6 Pauwels RA, Löfdahl C-G, Postma DS, et al. Effect of inhaled formoterol and budesonide on exacerbations of asthma. N Engl J Med 1997; 337: 1405-1411.

7 O’Byrne PM, Barnes PJ, Rodriguez-Roizin R, et al. Low dose inhaled budesonide and formoterol in mild persistent asthma. The OPTIMA randomized trial. Am J Respir Crit Care Med 2001; 164: 1392-1397.

8 Tattersfield AE, Löfdahl C-G, Postma DS, et al. Comparison of formoterol and terbutaline for as-needed treatment of asthma: a randomised trial. Lancet 2001; 357: 257-261.

9 Berggren F, Ekström T. A cost-effectiveness study compar-

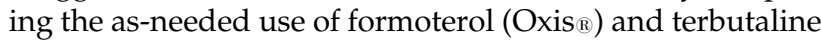
(Bricanyl ${ }^{\circledR}$ ) in patients with moderate to severe asthma. Respir Med 2001; 95: 753-758.

10 Pauwels RA, Sears MR, Campbell M, et al. Formoterol as relief medication in asthma: a worldwide safety and effectiveness trial. Eur Respir J 2003; 22: 787-794.

11 American Thoracic Society. Standards for the diagnosis and care of patients with chronic obstructive pulmonary disease (COPD) and asthma. Am Rev Respir Dis 1987; 136: 225-244.

12 Quanjer $\mathrm{PhH}$, Tammeling GJ, Cotes JE, Pedersen OF, Peslin R, Yernault J-C. Lung volumes and forced ventilatory flows. Report working party: Standardisation of lung function tests European Community for steel and coal. 
Official statement of the European Respiratory Society. Eur Respir J 1993; 6: Suppl. 16, 5-40.

13 Ind PW, Villasante C, Shiner RJ, et al. Safety of formoterol in Turbuhaler as reliever medication compared with terbutaline in moderate asthma. Eur Respir J 2002; 20: 859-866.

14 Roth M, Johnson PR, Rüdiger JJ, et al. Interaction between glucocorticoids and $\beta_{2}$-agonists on bronchial airway smooth muscle cells through synchronised cellular signalling. Lancet 2002; 360: 1293-1299.

15 Wallin A, Sandström T, Söderberg M, et al. The effects of regular inhaled formoterol, budesonide and placebo on mucosal inflammation and clinical indices in mild asthma. Am J Respir Crit Care Med 1999; 159: 79-86.

16 Wallin A, Sandström T, Cioppa GD, Holgate S, Wilson S. The effects of regular formoterol and budesonide on preformed Th-2 cytokines in mild asthmatics. Respir Med 2002; 96: 1021-1025.
17 Kips JC, O'Connor BJ, Inman MD, Svensson K, Pauwels RA, O'Byrne PM. A long-term study of the antiinflammatory effect of low-dose budesonide plus formoterol versus high-dose budesonide in asthma. Am J Respir Crit Care Med 2000; 161: 996-1001.

18 Aldridge RE, Hancox RJ, Robin Taylor D, et al. Effects of terbutaline and budesonide on sputum cells and bronchial hyperresponsiveness in asthma. Am J Respir Crit Care Med 2000; 161: 1459-1464.

19 Aldridge RE, Hancox RJ, Cowan JO, Frampton CM, Town GI, Taylor DR. Eosinophils and eosinophilic cationic protein in induced sputum and blood: effects of budesonide and terbutaline treatment. Ann Allergy Asthma Immunol 2002; 89: 492-497.

20 Jeffery PK, Venge P, Gizycki MJ, Egerod I, Dahl R, Faurschou P. Effects of salmeterol on mucosal inflammation in asthma: a placebo-controlled study. Eur Respir J 2002; 20: 1378-1385. 